
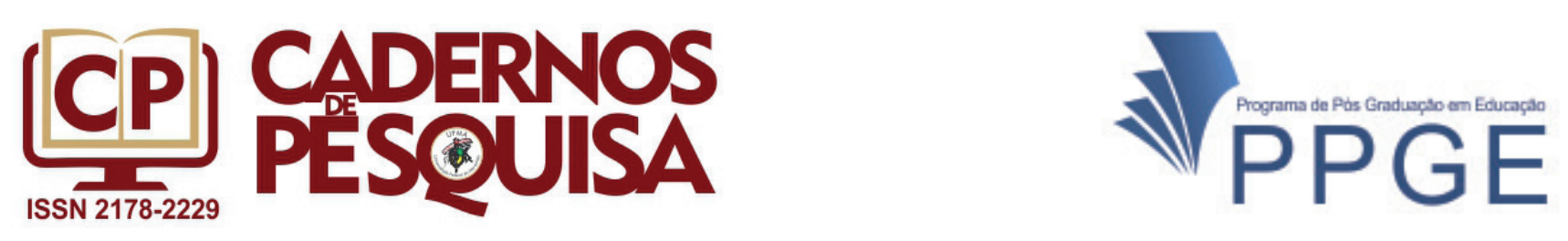

\title{
Panorama dos estudos sobre autoeficácia e satisfação no trabalho de docentes da educação básica
}

\author{
Overview of studies on self-effectiveness and satisfaction in \\ the work of teachers of basic education
}

\section{Panorama de los estudios sobre autoeficacia y satisfacción en el trabajo de docentes de la educación básica}

\author{
Enizete Andrade Ferreira \\ (iD http://orcid.org/0000-0002-5665-1254 \\ Erika Cristina de Carvalho Silva Pereira \\ iD $h t t p: / / o r c i d . o r g / 0000-0003-0701-9815$ \\ Maely Ferreira Holanda Ramos \\ https://orcid.org/0000-0001-6150-6345
}

\begin{abstract}
Resumo: Este artigo trata de uma revisão sistemática de estudos que investigam autoeficácia e satisfação no trabalho subsidiados pela Teoria Social Cognitiva de Albert Bandura. Objetivou-se explorar as temáticas dos estudos desenvolvidos sobre autoeficácia e satisfação no trabalho com professores da Educação Básica. Foi utilizado como técnica a Análise de Conteúdo segundo Bardin auxiliado, pelo software NVIVO 10. Para tanto foram feitas buscas em três bases de dados (Scielo, Redalyc e Capes), onde foram encontrados 23 artigos válidos para estudo de acordo com os critérios de inclusão pré-estabelecidos. O resultado deste trabalho revelou 16 (dezesseis) estudos com ênfase na autoeficácia docente, equivalente a 72,7\%; eles evidenciaram 16 subcategorias, das quais apresentaram destaques: (a) desempenho docente $(f=6) ;(b)$ colaboração entre professores ( $f=2$ ); Tecnologia de Informação e Comunicação (TIC) $(f=2)$; motivação $(f=2)$; inclusão ( $f=2$ ). Os que tratavam das categorias autoeficácia e satisfação simultaneamente alcançaram um total de $4(18,2 \%)$, em que as variáveis bem-estar docente e Burnout apresentaram, cada, maior frequência ( $f=2)$ e os que destacaram a categoria satisfação no trabalho incidiram 2 (duas) frequências $(9,1 \%)$, revelando escassez nos estudos sobre essa variável. É notável diante das respostas obtidas a partir análise dos dados, a importância das categorias supracitadas na ação docente.
\end{abstract}

Palavras-chave: Autoeficácia. Satisfação no trabalho. Professores. Teoria Social Cognitiva.

Abstract: This article deals with a systematic review of studies that investigate self-efficacy and job satisfaction subsidized by Albert Bandura's Cognitive Social Theory. The objective was to explore the themes of the studies developed on self-efficacy and satisfaction at work with teachers of Basic Education. The Bardin-assisted 
Content Analysis was used as a technique by the NVIVO 10 software. For this purpose, three databases were searched (Scielo, Redalyc and Capes), where 23 valid articles were found for study according to the inclusion criteria pre-established. The result of this study revealed 16 (sixteen) studies with an emphasis on teacher self-efficacy, equivalent to $72.7 \%$; they showed 16 subcategories, of which they presented highlights: (a) teaching performance $(f=6)$; (b) collaboration between teachers $(f=2)$; Information and Communication Technology $(I C T)(f=2)$; motivation $(f=2)$; inclusion $(f=2)$. Those that dealt with the self-efficacy and satisfaction categories simultaneously reached a total of $4(18.2 \%)$, in which the variables teacher well-being and burnout presented, respectively, a higher frequency $(f=2)$ and those that highlighted the satisfaction category in the 2 (two) frequencies $(9.1 \%)$, revealing a lack of studies on this variable. It is remarkable, given the answers obtained from the analysis of the data, the importance of the aforementioned categories in the teaching action. Keywords: Self-efficacy. Job satisfaction. Teachers. Cognitive Social Theory.

Resumen: Este artículo trata de una revisión sistemática de estudios que investigan autoeficacia y satisfacción en el trabajo subsidiados por la Teoría Social Cognitiva de Albert Bandura. Se objetivó explorar las temáticas de los estudios desarrollados sobre autoeficacia y satisfacción en el trabajo con profesores de la Educación Básica. Se utilizó como técnica el Análisis de Contenido según Bardin auxiliado, por el software NVIVO 10. Para ello se realizaron búsquedas en tres bases de datos (Scielo, Redalyc y Capes), donde se encontraron 23 artículos válidos para estudio de acuerdo con los criterios de inclusión predeterminado. El resultado de este trabajo reveló 16 (dieciséis) estudios con énfasis en la autoeficacia docente, equivalente al 72,7\%; que evidenciaron 16 subcategorías, de las cuales presentaron destaques: $(a)$ desempeño docente $(f=$ 6); (b) colaboración entre profesores ( $f=2)$; Tecnología de Información y Comunicación (TIC) ( $f=2)$; motivación $(f=2)$; inclusión ( $f=2)$. Los que trataban de las categorías autoeficacia y satisfacción simultáneamente alcanzaron un total de $4(18,2 \%)$, en que las variables bienestar docente y Burnout presentaron, cada, mayor frecuencia $(f=2)$ y los que destacaron la categoría satisfacción en el trabajo se centró 2 (dos) frecuencias $(9,1 \%)$, revelando escasez en los estudios sobre esa variable. Es notable ante las respuestas obtenidas a partir del análisis de los datos, la importancia de las categorías arriba citadas en la acción docente.

Palabras-clave: Autoeficacia. Satisfacción en el trabajo. Profesores. Teoría Social Cognitiva.

\section{INTRODUÇÃO}

\subsection{Teoria Social Cognitiva}

O estudo sobre o comportamento humano tem sido interesse de vários estudiosos da psicologia e da educação, dentre eles destaca-se Albert Bandura. Este teórico canadense graduou-se em psicologia, pela University of British Columbia - Canadá e prosseguiu sua formação a nível de mestrado e doutorado na Universidade de lowa, nos Estados Unidos, onde doutorou-se em Psicologia Clínica em 1952. A escolha pela psicologia aconteceu casualmente, isto é, foi por acaso que pegou um folheto sobre uma mesa da biblioteca que frequentava, com informações sobre um curso introdutório de psicologia; matriculou-se e, este curso, o influenciou sua opção na graduação (AZZI, 2014). Desse modo, nasceu um grande teórico, cujo trabalho tem contribuído em diferentes áreas de atuação como saúde, educação, esporte entre outros.

A Teoria Social Cognitiva emergiu de estudos sobre o comportamento humano, dentre eles o Behaviorismo de Skinner. Nessa linha teórica o processo de aprendizagem era o 
foco central, cujo interesse era compreendê-la a partir de estímulos ambientais e respostas do sujeito, seguidas contingentemente de consequências como reforço positivo; os eventos internos, ocorridos no interior do organismo, não eram considerados nesse processo, pois para Skinner interessava avaliar somente o que fosse observável externamente (ALMEIDA et al., 2013).

Bandura reconhece o valor dos estudos de Skinner no que diz respeito ao comportamento por associação entre estímulo e resposta, porém, sua teoria não se restringe a esse aspecto, pois acredita que as pessoas possuem elementos internos que as orientam a tomar decisões objetivadas para as quais podem prever, simbolicamente, as suas consequências. Com isso, percebe-se que as mudanças comportamentais, baseadas na observação, são mediadas cognitivamente. Para Bandura (2008), o aprendizado dos seres humanos não se limita a experiências diretas, podendo ser ativado pela observação (modelação) através do processo cognitivo. Contrapondo-se, assim, à visão de Skinner, que concebia o sujeito apenas como mero receptor (ROCHA, 2011).

A Teoria Social Cognitiva explica o comportamento humano, partindo de um sujeito particular e de suas relações com o contexto, em que fatores pessoais, ambientais e comportamentais interagem e influenciam-se bidirecionalmente. Esses indivíduos, cada um com suas particularidades, sofre ações do meio, mas também o influenciam. Assim, os sujeitos vivem em relação dialógica e de reciprocidade com o meio ao qual estão inseridos. Partindo dessa ideia, diz-se que o sujeito é agente, que pode influenciar sua própria ação para produzir determinados resultados (BANDURA, 1999). Isto é, os sujeitos têm a possibilidade de influenciar eventos, circunstanciais e moldar suas vidas (BANDURA, 2000).

A Teoria Social Cognitiva auxilia na compreensão do comportamento humano subsidiada por construtos que explicam como se dão as relações entre sujeito e ambiente e vice-versa. Por isso tem sido estudada em diferentes áreas de atuação, como saúde, esporte, psicologia, educação, entre outros (SILVA; LAUTERT, 2010; AZZI, 2014; TORISU; FERREIRA, 2009; JÚNIOR; WINTERSTEIN, 2010). Sendo assim, considera-se necessário discutir os processos extrínsecos e intrínsecos que influenciam o comportamento humano e a participação do ser agêntico.

\subsection{Autoeficácia}

O conceito de autoeficácia se origina nos anos de 1970 à luz das ideias de Albert Bandura, cujo termo nasceu da observação sobre o tratamento de pessoas fóbicas. Como conceito a autoeficácia ganha forma quando Bandura publica em 1977 o artigo denominado "Self-efficacy: Toward a Unifying Theory of Behavioral Change", no qual apresenta um quadro teórico integrador para explicar e prever mudanças psicológicas acentuadas por diferentes modos de tratamento (PAJARES, 1996). Esta teoria afirma que os procedimentos psicológicos, independentemente da forma, alteram o nível e a força da autoeficácia. É a hipótese de que as expectativas de eficácia pessoal determinam se o comportamento de 
enfrentamento será iniciado, quanto esforço será gasto e quanto tempo ele será sustentado diante de obstáculos e experiências aversivas (BANDURA, 1977). A autoeficácia destaca-se no núcleo da Teoria Social Cognitiva, pois orienta o pensamento e o comportamento que tem forte influência no funcionamento humano (BANDURA, 2008).

A autoeficácia está diretamente ligada à eficácia pessoal dos indivíduos tendo em vista que suas crenças orientam, em parte, suas ações. Sendo assim, as atitudes pessoais resultam mais daquilo em que acreditam do que em que realmente são capazes de realizar (BANDURA, 2000; 2008). Para tanto, as crenças de autoeficácia se desenvolvem por meio das influências de quatro fontes: experiências de domínio, experiências vicárias, persuasão social ou verbal e estados emocionais ou afetivos.

Experiências de domínio dizem respeito à conquista pelo próprio esforço. Depois que as pessoas se convencem de que têm o que é preciso para ter sucesso, perseveram diante da adversidade e rapidamente se recuperam dos contratempos (BANDURA, 1994). Experiências vicárias são as adquiridas por meio da observação de modelos. Pode-se relacionar essa característica à capacidade humana em adquirir habilidades a partir da experiência de outras pessoas com domínio no que fazem (GUERREIRO CASA-NOVA; POLYDORO, 2011). A persuasão social diz respeito a ser influenciado por outrem atrelado à possibilidade em alcançar sucesso em certas atividades (PAJARES; OLAZ, 2008). Estados emocionais ou afetivos, por sua vez, são inferências dos estados somáticos e emocionais indicativos de forças e de vulnerabilidades pessoais como ansiedade, estresse, sono ou cansaço que podem influenciar o grau de confiança sobre suas competências, baixando desse modo o nível de autoeficácia, podendo levar ao fracasso em uma atividade. No entanto, caso sua condição seja de bem-estar, pode elevar o nível de autoeficácia e a possibilidade de sucesso é maior (GUERREIRO CASA-NOVA; POLYDORO, 2011).

As crenças de autoeficácia influenciam a maneira como as pessoas pensam, seja de forma equivocada ou estratégica, otimista ou pessimista, seja a escala de cursos de ação a seguir e até mesmo os objetivos que estabelecem para si próprios e o seu empenho em relação a eles (BANDURA, 2000). De forma geral, Bandura pintou um retrato do comportamento humano e motivação em que as crenças que as pessoas têm sobre si mesmas são elementos-chave no exercício do controle e agência pessoal (PAJARES, 1996). No contexto educativo, esse construto mostrou fortes indicativos sobre o comportamento docente e suas ações.

\subsubsection{Autoeficácia Docente}

A autoeficácia docente, segundo Gonzalez et al. (2013), é um construto cuja origem também está na Teoria Social Cognitiva e faz referência às crenças que os professores possuem a respeito de sua própria capacidade em exercer influência positiva na aprendizagem dos alunos, mesmo daqueles que apresentam dificuldade ou desmotivação (PEDRO, 2007). Nessa mesma linha teórica Azzi e Vieira (2014) afirmam que o professor, quando avalia sua competência na docência, parte daquilo que lhe é exigido em relação ao ensino, considerando os elementos contextuais que se fazem presentes no lócus de sua prática. Essa 
autoavaliação proporciona um olhar sobre a relação entre dificuldades, habilidades e capacidades imprescindíveis para a obtenção de sucesso no processo ensino-aprendizagem.

Os resultados de vários estudos voltados à autoeficácia docente sugerem que esse é um construto importante para a compreensão do comportamento dos professores em relação aos seus colegas de trabalho (CASTRO-CARRASCO et al., 2012; CASTRO SILVA; MARQUES SILVA, 2015), em relação aos alunos (PAIVA; PEREIRA DEL PRETTE, 2009) e, sobretudo no que diz respeito ao desenvolvimento de sua prática docente (RODRÍGUEZ et al., 2009).

Por conseguinte, os pensamentos, as ações e as emoções influenciam-se mutuamente orientados pela autoeficácia, fazendo com que as percepções dos sujeitos orientem suas ações e, estas pelo seu efeito, as modifiquem. Outrossim, o nível de crença sobre suas habilidades ou conhecimentos sobre algo irá determinar o grau de compromisso em alcançar objetivos propostos (BANDURA, 1977).

As crenças de autoeficácia podem exercer notável influência no comportamento de docentes e consequentemente, sua amplitude pode, também, refletir no desenvolvimento de alunos e alunas no espaço escolar (SILVA, 2012). Isso ocorre porque sua influência no processo de ensino contribui com as tomadas de decisões sobre o fazer pedagógico e na relação com os alunos, pois suas crenças promovem uma seleção sobre como agir ou reagir a determinadas situações em sala de aula (PAIVA; PEREIRA DEL PRETTE, 2009).

Os espaços estruturais em torno dos quais as pessoas organizam suas vidas (família, sociedade e trabalho) irão definir suas crenças de autoeficácia (PEDRO, 2007). Isso significa que o professor deve ser visto a partir dos elementos com os quais se relaciona e ao contexto ao qual está inserido. E, perante as possibilidades positivas da autoeficácia em relação ao processo educativo é importante saber que as crenças de autoeficácia dos professores precisam ser construídas. Assim, saber como se dá esse processo é fundamental para que a ação docente equalize os saberes presentes no espaço escolar para construção de práticas e ações eficientes no processo ensino-aprendizagem. Também, é importante que o educador se sinta motivado no local de trabalho; um dos motivadores para essa condição, além da autoeficácia, é estar satisfeito com o trabalho. Logo, essa condição é elemento essencial para aguçar a criatividade e a resiliência docente.

\subsection{Satisfação no Trabalho}

O final do século XX e início do século XXI apresentou um novo modelo de produção - o Toyotismo - que surge como saída à crise do capitalismo e vislumbra mudanças na forma de organização trabalhista, ordem social e regulação compactuada entre capital, trabalho e Estado (ANTUNES, 2015). Esse modelo apresenta algumas características como polivalência, flexibilização e alongamento de jornada de trabalho, gerando resultados como a intensificação do trabalho em que o ritmo e a velocidade, a cobrança de resultados, a versatilidade, a acumulação de tarefas e mais tempo no trabalho acabam por se tornarem comuns no dia a dia das pessoas. 
Diante dessas mudanças vislumbra-se um novo perfil de trabalhador, com capacidade para assumir múltiplas tarefas quando for necessário e, em alguns casos, com tempo estipulado, por isso, exige-se várias habilidades, alterando seus modos de ser e fazer (ANTUNES, 2015). Isso provoca a intensificação do trabalho que pode desencadear mal-estar como estresse e desequilíbrio entre vida pessoal e profissional (COUTO, 2012).

Vários estudos foram realizados sobre esse tema em virtude das consequências das transformações no mundo do trabalho (DALL ROSSO, 2008; ALVES, 2011; FARIAS et. al., 2013; FIGUEIREDO, 2012; MARQUEZE; MORENO, 2009). Assim, pesquisas feitas por economistas, voltaram-se para a questão econômica; os sociólogos estudaram gênero, raça e posição social, a psicologia, por sua vez, direcionou-se mais para as consequências da satisfação no local de trabalho (COUTO, 2012). Os estudos na área educacional também tomaram como fio condutor as consequências no local de trabalho, em função de pesquisas que demonstraram que a satisfação no trabalho pode influenciar no processo ensino-aprendizagem de modo significativo para a qualidade de ensino (IAOCHITE et al. 2011).

Para Lemos e Passos (2012), a satisfação no trabalho é um estado particular, que pode se alterar de uma pessoa para outra. Para Paula e Queiroga (2015), é resultante de práticas vivenciadas no cotidiano do trabalho que proporcionaram bem-estar ao trabalhador. Andrade et. al. (2015) compreendem que é um estado emocional do trabalhador em consequência das situações que vivencia em seu cotidiano laboral.

Estar satisfeito é condição essencial para que o trabalho seja desenvolvido com prazer. Esse estado de bem-estar é desencadeado, de acordo com as ideias supracitadas, por um conjunto de fatores que interagem e podem estar envolvidos com o crescimento e o desenvolvimento pessoal e a determinados fatores que envolvem as condições estruturais de trabalho. Além disso, pode ser um importante revitalizador e motivador para o entusiasmo em serviço (MACHADO et al., 2011).

Segundo Marqueze e Moreno (2009), o estado emocional do trabalhador pode definir sua atuação. Assim, o bem-estar é uma condição que pode promover atitudes positivas de enfrentamento à vida levando à satisfação dos trabalhadores. A esse respeito, Ramos (2015) acrescenta que a satisfação pode estar associada também ao grau de afetividade em relação a função que é desempenhada, proporcionando-lhe sensação agradável e positiva. O emocional sugere o motivo de muitas pessoas permanecerem no trabalho, visto que isto as deixa felizes com suas funções.

Diante dessas possibilidades e ao nível motivacional que representa a satisfação no trabalho para a vida de homens e mulheres, é válido avaliar esse processo na vida de docentes (RAMOS, 2016).

\subsubsection{Satisfação no Trabalho Docente}

De modo geral, percebe-se que o nível de satisfação pode ter forte influência na maneira como os indivíduos executam tarefas. Em se tratando de docentes, pode 
contribuir com práticas pedagógicas mais criativas, as quais os tornarão profissionais mais envolvidos, dedicados e comprometidos com o desenvolvimento da aprendizagem dos alunos. Portanto, o resultado do desempenho docente tem sido associado à sua satisfação, posto que deste estado a consequência é a obtenção de melhores resultados (RAMOS, 2016).

As pesquisas sobre satisfação no trabalho, nas escolas, subsidiadas pela Teoria Social Cognitiva, vêm sendo relacionadas ao resultado do processo ensino-aprendizagem e tem como suporte o Modelo Social Cognitivo de Satisfação no Trabalho, criado com o objetivo de descobrir elementos potencialmente preditores da satisfação (RAMOS, 2015).

Apoiada na Teoria Social Cognitiva de Albert Bandura, o Modelo Social Cognitivo de Satisfação no Trabalho é um elemento de suporte aos estudos acerca da satisfação no trabalho docente criado por Duffy e Lent (2009), cuja proposta é analisar de forma integrada o conjunto de elementos que compõe o contexto educativo. A satisfação no trabalho, com base nesse modelo, pode ser explicada por meio de 7 (sete) variáveis: (a) apoio de eficácia relevante - diz respeito à colaboração dos colegas de trabalho; (b) condições de trabalho - referente à percepção do sujeito sobre as condições de trabalho; (c) progresso de objetivos - quando se percebe o sucesso alcançado pelas metas desenvolvidas; (d) afeto positivo - quando se desenvolvem emoções positivas por um ambiente acolhedor no local de trabalho; (e) autoeficácia docente - a crença em desenvolver com sucesso suas funções na escola para a melhoria do processo ensino-aprendizagem; (f) satisfação no trabalho; (g) satisfação com a vida. Essa é uma nova composição que surgiu em 2011 quando foram incluídas as categorias "satisfação com a vida" e "apoio de eficácia relevante", esta última veio a substituir "metas de apoio"; o motivo da inclusão da variável "satisfação com a vida", justifica-se pela influência direta desta sobre a satisfação no trabalho docente (RAMOS, 2015).

Devido às diferentes realidades vividas por professores, estudos como o de Ramos (2015) indicam mais variáveis explicativas considerando-se outros elementos do contexto local que podem influenciar a percepção dos docentes acerca daquilo que pode deixá-los satisfeitos. No caso do estudo supracitado a variável "satisfação com o salário" ganhou destaque. Essa variável pode indicar a percepção dos docentes a respeito de sua condição profissional pouco valorizada frente às responsabilidades que a profissão exige. Esse fato acrescido à intensificação e à precarização do trabalho (DALL ROSSO, 2008) pode, também, ter seu grau de influência sobre as ações docentes.

Os textos analisados neste estudo apontam a relação direta entre satisfação docente, desenvolvimento profissional e melhoria no processo ensino-aprendizagem relevando, desse modo, o grau de importância do professor enquanto elemento-chave a ser considerado nas políticas públicas voltadas às reformas educativas. Neste sentido o contexto ao qual o educador está inserido, suas relações pessoais e de apoio, devem ser avaliados. 


\section{METODOLOGIA}

Este é um estudo de revisão sistemática da literatura, voltado para a elaboração de uma visão panorâmica sobre a autoeficácia e a satisfação no trabalho docente. Para tanto, foram estabelecidas fases a fim de identificar, selecionar e avaliar criticamente o material. De acordo com a Colaboração Cochrane - uma instituição reconhecida mundialmente por seguir métodos rigorosos para pesquisas de revisão sistemática (RAMOS, 2015) - deve- se cumprir sete etapas: a) formulação da pergunta problema; b) localização e seleção dos estudos; c) avaliação crítica dos estudos; d) coleta dos dados; e) análise e apresentação dos dados; f) interpretação dos dados; (g) aprimoramento e atualização da revisão (RAMOS, 2015).

Na primeira etapa, formulação da pergunta, foi utilizada a técnica PVO (RAMOS, 2015), onde $P$ - refere-se à situação-problema, participantes ou contexto, no caso: Qual o panorama das pesquisas sobre autoeficácia e satisfação no trabalho docente?; V - aponta para as variáveis do estudo (autoeficácia e satisfação no trabalho) e O - refere-se ao resultado (outputs) esperado pelo estudo, isto é, a identificação de panorama nacional e internacional (em português e espanhol).

A etapa 2, localização e seleção dos estudos, foi desenvolvida em sub-etapas, quais sejam: (1) definição dos diretórios de buscas, optando-se pelas seguintes bases de dados: CAPES, SCIELO e REDALYC; (2) definição dos descritores; (3) definição das equações de busca - foram aplicadas duas estratégias em forma de equação (português e espanhol) quais sejam: "(Autoeficácia ou Crenças de autoeficácia OR Crenças de eficácia) AND (Docente OR professor) AND (teoria social cognitiva)" e "(Satisfação no trabalho OR satisfação profissional OR bem estar no trabalho OR bem estar profissional OR Modelo Social Cognitivo de Satisfação no Trabalho) AND (Docente OR professor)", em português, e "(Autoeficacia o creencia de autoeficacia o creencia de eficácia) y (Docente o professor) y (a teoria cognitiva social)" e "(Satisfacción en el trabajo o satisfacción professional o bienestar professional o modelo social cognitivo de satisfacción em el trabajo) y (Docente o profesor)" em espanhol.

A quarta subetapa (4) foi a construção dos cruzamentos a partir das equações de busca; (5) Foram adotados critérios de inclusão para delimitar as buscas, quais sejam: somente artigos; dos últimos 10 anos (2007 a 2017), os disponíveis na íntegra, os gratuitos, os revisados por pares, que tratassem de professores da Educação Básica, com os principais descritores no título ou nas palavras chave e que contemplassem a Teoria Social Cognitiva, artigos nacionais e internacionais em português e espanhol.

$\mathrm{Na}$ fase 3, avaliação da relevância dos achados, foram aplicados dois testes de relevância, com perguntas objetivas. As perguntas foram: o estudo está de acordo com o tema investigado? Foi publicado no período estipulado? É um estudo envolvendo professores da educação básica? Foi publicado nos idiomas propostos? Tem acesso livre a 
pesquisadores (acesso ao texto completo)? Utiliza a Teoria Social Cognitiva como base de fundamentação?

O Teste II, inspirado em Ramos (2015), foi feito somente com os artigos pré-selecionados no Teste I, realizados por dois juízes independentes, com conhecimento na área.

$\mathrm{Na}$ coleta de dados (fase 4) decidiu-se investigar duas variáveis, sendo estas "os objetivos" e as "palavras-chave" dos estudos para identificação das categorias temáticas mais exploradas pelos pesquisadores.

Para análise de dados (fase 5) utilizou-se a técnica de Análise de Conteúdo segundo Bardin (1977) que é um conjunto de procedimentos sistemáticos e objetivos que visam obter os principais conceitos ou temas abordados em um texto. É uma técnica efetivada por meio de algumas etapas: pré-análise, exploração do material e tratamento dos resultados (SANTOS, 2012).

Na pré-análise organiza-se o material compondo o corpus da pesquisa. Esta fase possui três dimensões: escolha dos textos para serem analisados, formulação das hipóteses e dos objetivos e a elaboração dos indicadores que fundamentam a interpretação final. Este processo levou às categorias de análise "autoeficácia" e "satisfação no trabalho". A análise se efetivou com uso do software Nvivo 10 para estudo de frequência dos objetivos dos artigos investigados e o Mendeley. Por fim, realizou-se a interpretação dos resultados e o aprimoramento da revisão (fases 6 e 7).

\section{RESULTADOS E DISCUSSÕES}

\subsection{Resultados das buscas}

O resultado das buscas foi organizado em um único quadro, de modo a evidenciar o número de artigos encontrados e os diretórios de buscas para dar uma visão geral sobre os achados desde o levantamento inicial até se chegar aos válidos para esta revisão.

\begin{tabular}{|l|c|c|c|}
\hline Diretório & Levantamento inicial & Refinamento após os critérios & Inclusão final* $^{*}$ \\
\hline Scielo & 40 & 08 & 07 \\
\hline Capes & 528 & 08 & 08 \\
\hline Redalyc & 235 & 24 & 08 \\
\hline
\end{tabular}

*com exclusão dos objetos repetidos

Fonte: Ferreira (2018)

Em síntese, considerando a incidência em todas as bases de dados supracitadas identificou-se que o processo de refinamento realizado no levantamento inicial resultou num total de 41 artigos. No decorrer do processo foram excluídos 16 artigos (39,02\%) em virtude de repetição, de não estarem disponível na íntegra ou, por não corresponderem aos 
critérios de inclusão mencionados anteriormente. Depois desse refinamento inicial restaram 25 artigos $(60,97 \%)$ para análise. O teste de relevância I, resultou na exclusão de 2 (dois) textos representando em percentual de $8 \%$ em relação ao quantitativo após o refinamento. Desse modo, 23 (vinte e três) foram considerados válidos para revisão e dois textos foram excluídos por não tratarem da educação básica.

No teste de relevância II, os juízes concordaram com a exclusão de mais 1 (um) estudo pelo fato de não estar diretamente relacionado ao tema pesquisado. Após os cálculos notou-se que o Índice de Concordância (IC) quanto a este estudo em questão foi de 33\%, confirmando o percentual dentro dos padrões para exclusão, pois o ponto de corte estabelecido para inclusão foi IC $=$ ou $>80$. Com isso restaram 22 (vinte e dois) trabalhos válidos para revisão sistemática.

\subsection{Caracterização dos artigos}

Para caracterizar os objetos foram levantados dados sobre: (1) ano de publicação; (2) local de publicação; (3) tipo do estudo - metodologia. Desse modo, pode-se ter um panorama das pesquisas que estão sendo desenvolvidas, local de realização e qual metodologia tem sido mais frequente. Quanto ao ano de publicação dos artigos as análises resultaram no Gráfico 1.

\section{Gráfico1: Frequência por ano de publicação}

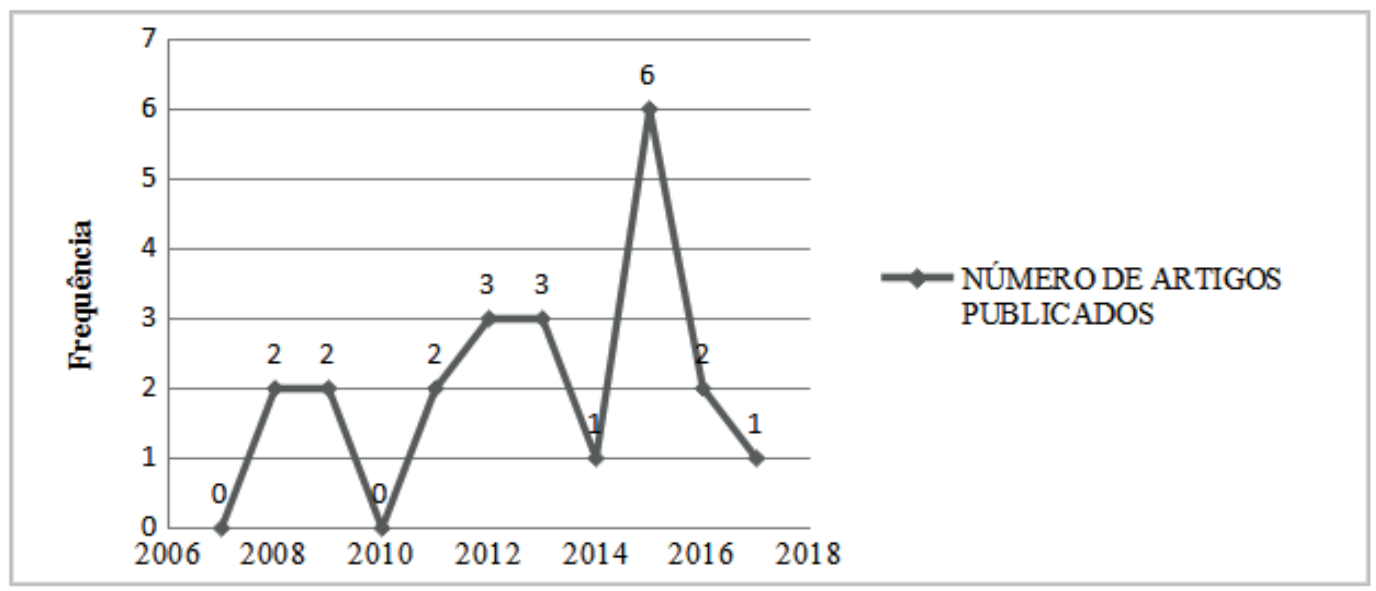

Fonte: Ferreira (2018)

Dos trabalhos encontrados com publicação nos últimos 10 anos, o ano de 2015 apresenta maior incidência ( $f=6$ ) e os anos de 2014 e de 2017, menor número de publicações, correspondendo 1 (um) artigo em cada ano referido. Ressalta-se que no ano de 2007 não foi encontrado artigo válido para este estudo. Essas buscas foram realizadas até meados de junho de 2017. 
Quanto ao local de publicação notou-se que $50 \%$ ( $f=11)$ dos objetos levantados eram publicações de estudiosos no Brasil, dentre os quais 10 (dez) pertencem às regiões sul ( $\mathrm{Pa}$ raná e Rio Grande do Sul) e sudeste (São Paulo e Rio de Janeiro) e 1 (um) à região norte, da cidade Belém-PA; 13,6\% (3) no Chile; 13,6\% (3) na Espanha; 13,6\% (3) na Colômbia; $4,6 \%$ (1) em Portugal e 4,6\% (1) no Peru.

Dos textos analisados $81,8 \%(f=18)$ desenvolveu estudos empíricos e 18,2\% ( $f=4)$ pesquisas teóricas. As análises quantitativas ganharam destaque em 72,7\% (f=16) dos estudos selecionados; as qualitativas representaram $18,2 \%(\mathrm{f}=4)$ da metodologia utilizada e os estudos com método quanti e quali tiveram menor frequência $9 \%(f=2)$ no material válido para revisão.

O resultado dessas buscas mostrou que a minoria dos trabalhos utiliza o método quanti e quali, porém estudos evidenciam que a utilização do método misto pode enriquecer os resultados da pesquisa, visto que há uma complementaridade nas informações adquiridas que ampliar as análises dos fenômenos estudados (FERNADEZ, 2015; GATTI, 2004).

\subsection{Análise dos objetivos e Síntese categorial: Identificando tendências do campo de pesquisa.}

A proposta central desta revisão sistemática foi desenvolver um estudo sobre os objetivos dos artigos encontrados nas bases de dados supracitadas para verificar o que tem se estudado sobre autoeficácia e satisfação no trabalho de docentes da Educação Básica. Para tanto, realizou-se um processo de codificação visando indicar uma síntese categorial. Desse modo foi gerado o gráfico 2.

Gráfico 2: Percentual de incidência dos grupos categoriais

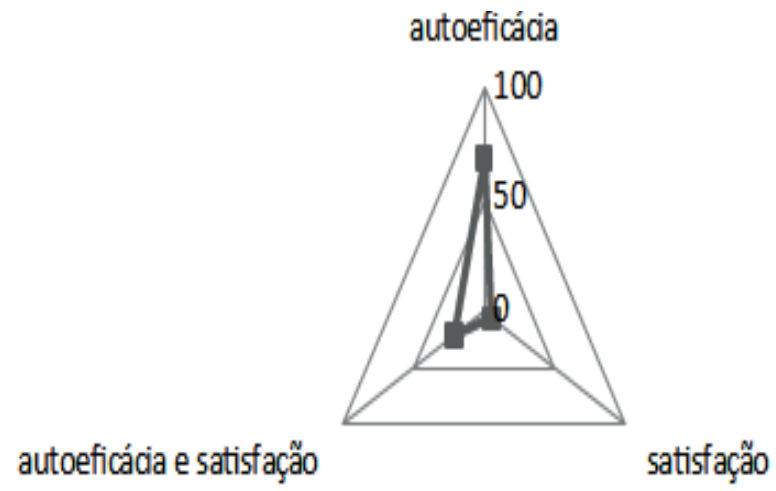

Fonte: Ferreira (2018)

O gráfico 2 é um output gerado pelo software NVIVO 10 e mostra que a maioria dos trabalhos revelados pela busca que deram ênfase à categoria autoeficácia e somaram um total de 16 (72,7\%); os que tratavam das duas categorias: autoeficácia e satisfação simulta- 
neamente alcançaram um total de 4 (quatro) com 18,2\% e os que destacaram a categoria satisfação no trabalho incidiram 2 (duas), frequências $(9,1 \%)$.

Esses dados indicam que as pesquisas sobre a autoeficácia são mais frequentes considerando o campo da Teoria Social Cognitiva no Brasil. Percebe-se que a satisfação no trabalho, nesta perspectiva, ainda é uma categoria pouco explorada e os resultados dos estudos aqui apresentados, sugerem a importância desse construto na vida profissional dos docentes.

\subsection{Artigos que investigaram exclusivamente a autoeficácia docente}

Como visto, este foi o grupo categorial mais incidente. Ao aplicar o processo de codificação pela Análise de Conteúdo (AC), com o auxílio do software NVIVO 10, foi possível identificar 17 subcategorias associadas (Gráfico 3). A identificação destes termos aponta para fatores com os quais a autoeficácia tem sido mais relacionada e investigada em conjunto.

Gráfico 3: Subcategorias associadas à autoeficácia nos artigos investigados.

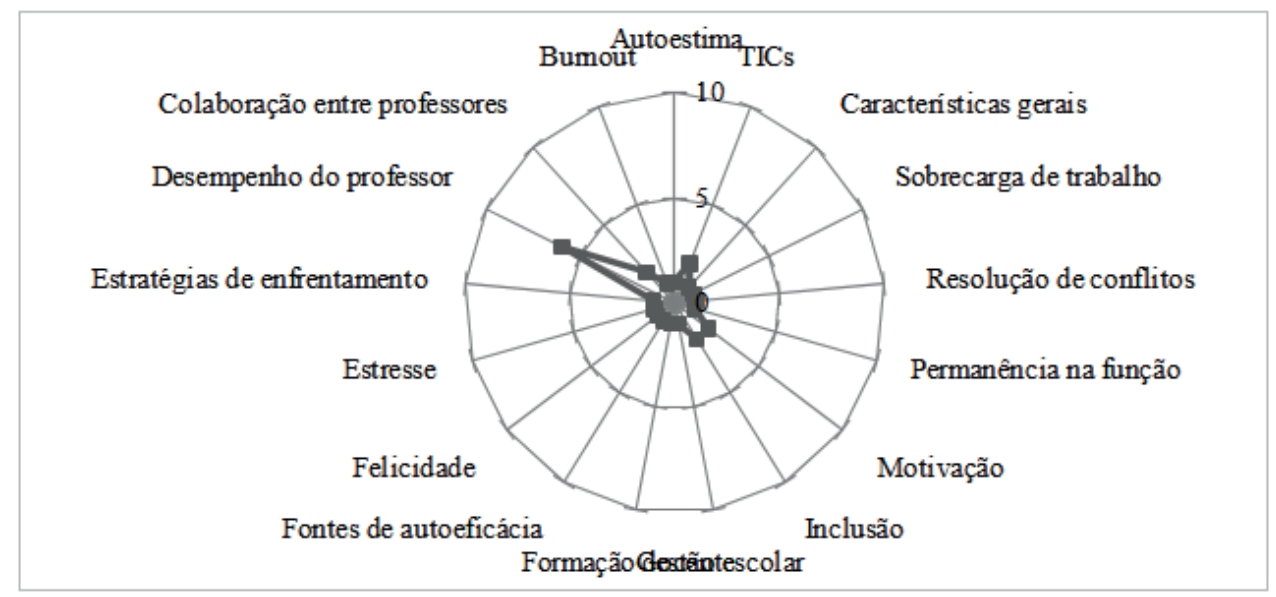

Fonte: Ferreira (2018)

Objetivou-se analisar as subcategorias mais frequentes, para tanto tomou-se como ponto de corte termos com frequência absoluta $>1$. Sendo assim os mais frequentes foram: (a) desempenho de professores $(f=6)$; (b) colaboração entre professores $(f=2)$; Tecnologia de Informação e Comunicação (TIC) $(f=2)$; motivação ( $f=2)$; inclusão $(f=2)$. Como é possível notar no gráfico 3, as demais subcategorias alcançaram frequência 1.

\subsubsection{Desempenho de professores}

O professor possui destaque no meio educacional devido sua importância no processo ensino-aprendizagem. Assim, suas ações e práticas devem ser consideradas como fio condutor de conhecimento e, para além, sua formação, que será um dos elementos de orientação para 
suas ações, que culmina em seu desempenho em sala de aula. Desse modo, essa subcategoria é a mais incidente e aparece em 6 (seis) estudos aqui encontrados. Os estudos em que se destacou o desempenho docente relacionado a autoeficácia indicaram que o docente pode ser influenciado por diferentes elementos que se entrelaçam em sua vida pessoal e profissional corroborando a ideia de que o desempenho docente, traduzido em suas ações pedagógicas, pode influenciar fortemente o processo ensino-aprendizagem (FERNANDEZ, 2015).

Fernández-Arata (2008) estudaram a relação entre objetivos, estratégias de ensino, autoeficácia e desempenho docente em professores da educação primária de Lima Metropolitana. Participaram 313 professores, dos quais 224 do sexo feminino e 89 masculinos. Para medir a orientação para o objetivo do professor se utilizou a escala Patterns of Adaptive Learning (Padrões de Aprendizagem Adaptativa) (PALS, 1997, 2000), traduzida e adaptada por Lennia Matos (2005). Para medir as estratégias de aprendizagem e metacognição dos professores realizou-se uma adaptação do questionário Motivated Strategies for Learning (MSQL-1991) para estudantes, utilizado por Lennia Matos (2005), este é um instrumento de auto-avaliação. Quanto à medição da autoeficácia utilizou-se a escala de autoeficácia percebida de professores, construída por Tschannen-Moran y Woolfolk (2001). Também se utilizou o questionário de autoavaliação do desempenho docente (Fernández, 2002), considerando-se as dimensões propostas Por Valdés (2000b): a) Capacidades pedagógicas, b) Emocionalidade, c) Responsabilidade no desempenho de suas funções de trabalho, d) Relacionamentos interpessoais com seus alunos, pais, professores e comunidade escolar em geral e, e) Resultados do seu trabalho educacional. Os resultados indicaram uma relação positiva entre as variáveis, identificou-se ainda que o desempenho docente e os níveis de estratégias podem ser influenciados pela autoeficácia.

Paiva e Pereira Del Prette (2009) estudaram as crenças educacionais de professores para saber que práticas pedagógicas são desenvolvidas em sala de aula e, de que forma, isso pode impactar no aprendizado dos alunos. Fizeram parte da pesquisa 33 professoras que lecionavam nas primeiras séries do Ensino Fundamental de nove escolas públicas de São Paulo. Foi utilizado como instrumento de coleta de dados um questionário de avaliação de crenças do professor (QAC-P) que é composto por questões abertas e fechadas configurando-se em uma pesquisa mista. A pesquisa classificou dois grupos de professoras (facilitadoras e dificultadoras) em que as facilitadoras, sugerem que existe um processo extrínseco e influenciador que pode levar ao fracasso dos alunos e, por isso, os componentes do processo-ensino aprendizagem precisam ser avaliados; já as dificultadoras relacionam o fracasso aos alunos. Os resultados apontam o não reconhecimento fundamental docente no processo ensino aprendizagem, o que leva a contradição entre discurso e prática pedagógica. Os autores sugerem, ainda, investigações adicionais, já que os discursos dos professores que se diziam capazes para desenvolver um trabalho colaborativo ao aprendizado dos alunos, nem sempre era percebido na prática. Desse modo, a crença docente sobre sua capacidade parece que nem sempre está relacionada à sua prática, por isso precisam ser avaliadas variáveis que possam explicar melhor esse fenômeno. 
Castro-Carrasco et al. (2012) estudaram a autoeficácia em docentes no início de carreira com o objetivo de verificar aspectos positivos e/ou negativos que podem comprometer o desempenho em sala de aula. Neste estudo utilizou-se a entrevista como instrumento de coleta de dados com 4 (quatro) participantes com quem se realizou 12 entrevistas. O trabalho de Castro-Carrasco (2012) apresentou a importância do impacto conhecido como fenômeno "choque de realidade" nos quatro professores, o valor dado aos processos motivacionais e a importância da persuasão social, ou socialização profissional na inserção de professores.

Apablaza e Lira (2013) realizaram uma revisão de literatura sobre autoeficácia em professores chilenos e constataram a escassez de estudos sobre o assunto demonstrando preocupação, já que esse construto tem sido evidenciado como elemento importante para o desempenho docente e consequentemente para o processo ensino-aprendizagem; pouco conhecimento sobre suas próprias capacidades para ensinar e desenvolver a aprendizagem nos estudantes é desconhecer um fator transversal da pedagogia, por isso, finalizam o estudo com uma síntese sobre os sentimentos de autoeficácia nos professores.

Covarrubias e Lira (2015) investigaram o sentimento de autoeficácia e o desempenho de professores chilenos em uma amostra com 544 docentes, por se ver a importância da prática pedagógica para o processo ensino-aprendizagem. Utilizou-se como instrumento um questionário adaptado e traduzido "Teacher Sense of Efficacy Scale" (TSES) de Tschannen-Moran e Woolfolk (2001). O resultado sugere que a experiência docente é um fator que auxilia significativamente as crenças de autoeficácia e, por conseguinte, o desempenho dos professores.

Covarrubias-Apablaza e Mendonza-Lira (2016) desenvolveram estudo sobre crenças de autoeficácia docente em diferentes níveis de ensino, partindo da ideia de que a educação escolar deve promover o desenvolvimento intelectual dos alunos e a motivação intrínseca, desde que adquiram competências para que consigam desenvolvê-la o resto da vida. Participaram do estudo 544 professores chilenos da área urbana por nível de ensino (jardim da infância, primário e secundário) e administração. O estudo revelou diferenças de crenças de autoeficácia entre os docentes, mas não pela diferença de níveis e sim pelo tipo de gestão escolar. Percebe-se com isso que o nível de crença de autoeficácia docente pode estar relacionado a outros fatores que estão interligados a figura docente.

\subsubsection{Colaboração entre professores}

O trabalho em equipe pode contribuir com o crescimento do grupo a nível profissional. Em se tratando de docentes, o trabalho coletivo pode influenciar no ambiente escolar e no resultado do aprendizado dos alunos. Por isso, a subcategoria colaboração entre professores foi revelada em 2 (dois) estudos como contributo necessário em grupos de professores para o desenvolvimento de atividades criativas e dinâmicas que possam melhorar o fazer educativo.

O estudo de Silva e Silva (2015) sugere que a percepção da autoeficácia pode aumentar o interesse por obtenção de novos conhecimentos e a partilha de informação entre os grupos, melhorando relações de trabalho e oportunizando um trabalho mais produtivo dentro do 
espaço escolar. A pesquisa envolveu 82 professores de escolas do $2^{\circ}$ e $3^{\circ}$ ciclos de Portugal e foram utilizadas como instrumentos três escalas. Uma do tipo Likert para avaliar o envolvimento na prática, uma escala de medida do interesse pela colaboração, construída a partir de um questionário de Wade et al. (1994) e uma escala para avaliar as crenças de autoeficácia docente, tendo como base o instrumento Teacher Self-Efficacy in Behavior Management and Discipline Scale (SEBM) desenvolvido por Emmer e Hickman (1991), o qual complementou a Teacher Efficacy Scale (TES) de Gibson e Dembo (1984), integrando o tema da gestão de sala de aula. Os principais resultados sugerem que os professores que se autopercebem como mais autoeficazes estão mais dispostos a colaborar. Desse modo, quanto mais elevado o nível de autoeficácia maior a tendência em desenvolver práticas colaborativas.

\subsubsection{Tecnologias de Informação e Comunicação (TIC)}

O uso de tecnologias está presente no cotidiano das pessoas, por isso, estabelecer uma estreita relação com esse tema é importante e necessário na vida dos docentes. Embora algumas escolas não estejam providas de recursos tecnológicos, a clientela que a frequenta pode ter bastante intimidade com as novas tecnologias. Conhecer sobre o uso das tecnologias tornou-se indispensável a qualquer profissional. A inquietude sobre 0 assunto pode ser evidenciada em 2 (dois) estudos que relacionam a percepção de crenças docentes e o uso dos computadores para o ensino em sala de aula.

Bustos Navarrete (2012) estudou a relação entre cinco tipos de crenças docentes e o ensino com o uso de computadores para verificar qual tipo de crença tem sido mais efetiva nas atividades pedagógicas. Neste estudo se utilizou uma amostra não probabilista de voluntários em que se dispuseram 112 professores de cinco estabelecimentos chilenos e se utilizou questionários e escalas para obtenção dos dados. $O$ autor destaca a importância da autoeficácia computacional e as crenças sobre a efetividade das Novas Tecnologias de Informação e Comunicação (NTIC) na educação para se compreender a frequência e variedade de uso de NTIC de professores. Os resultados indicaram que o uso efetivo da tecnologia pelos professores depende de sua confiança, tanto no manejo pessoal quanto em sua aplicação no ensino.

Pedro e Piedade (2013) desenvolveram estudos sobre cursos de formação presencial em TIC's e o desenvolvimento da autoeficácia de professores relacionados a utilização de computadores. Este trabalho foi desenvolvido com um grupo de 103 professores de uma escola pública do ensino básico e secundário Português onde analisou os efeitos da formação presencial na área das TIC especificamente, sobre o sentido de autoeficácia na utilização dos computadores e o índice de utilização das tecnologias nas práticas docentes. Para obtenção dos dados foi utilizado um questionário através da ferramenta online googledocs. Os resultados sugerem que o curso presencial influencia favorável e significativamente os níveis de utilização e o sentido de autoeficácia dos professores. 


\subsubsection{Motivação}

A motivação é um estado emocional que pode ser gerado pela condição de bem-estar, proporcionada no local de trabalho. Estar motivado é condição essencial para o exercício de qualquer função profissional, mais ainda na função docente, que lida diariamente com a diversidade em um espaço micro. Assim, essa subcategoria foi evidenciada em 1 (um) estudo relacionado a autoeficácia docente.

Goya et al. (2008) desenvolveram estudo sobre crenças de eficácia em professores de física do Ensino Médio relacionando-as ao nível de motivação dos alunos. Participaram da pesquisa 20 professores e 200 alunos do Ensino Médio e os instrumentos utilizados para coleta de dados foram questionário e escala. O resultado mostra que as crenças de eficácia pessoal de professores relacionam-se positivamente com a motivação dos alunos para aprender física. Pode-se dizer que as crenças de autoeficácia estão ligadas à motivação dos alunos e ao uso de estratégias pessoais de estudo. Os autores sugerem o uso de estratégias motivacionais no ensino de física, bem como novas pesquisas para ampliação do conhecimento na área.

\subsubsection{Inclusão}

Pensar em inclusão significa incluir a todos e, no aspecto educativo, é tornar possível a permanência de alunos e suas diferenças, seja de classe social, etnia, condição física ou intelectual em uma escola. Para isso, é importante proporcionar as condições básicas necessárias. No caso, a estrutura física do prédio, bem como a parte pedagógica precisam ser reavaliadas, o que exige também, nesse caso, a formação de professores e da equipe escolar de um modo geral (GLAT et al., 2007).

Conhecer o assunto é importante e necessário dentro do atual contexto educacional que torna obrigatório o atendimento de crianças com necessidades educativas especiais. No caso da inclusão, são todas as crianças com deficiência ou não, mas que necessitem de atendimento especializado. Neste sentido, evidenciou-se esta subcategoria em 2 (dois) estudos.

Sanini e Bosa (2015), investigaram as crenças de uma educadora sobre o desenvolvimento de seu aluno com autismo, na educação infantil, Para tanto sua amostra foi uma professora da rede privada de educação infantil e como técnica utilizou-se entrevista a partir de um questionário específico para realização da entrevista com questões semidirigidas e que teve como eixos norteadores: conhecimento sobre o autismo; sentimentos em relação ao trabalho; práticas utilizadas; percepção sobre o desenvolvimento e aprendizagem da criança, bem como sobre o apoio e/ou orientação Os resultados mostraram que a aceitação e o reconhecimento do potencial do aluno (crenças), por parte da educadora, tenderam a ser determinantes para a sua prática.

Segundo Dias (2017), são poucas as pesquisas que tratam de práticas inclusivas tendo como pressuposto o preparo docente para inclusão educativa. Por isso, desenvolveu estudo para avaliar a percepção docente sobre sua habilidade na efetivação dessas 
práticas. A amostra foi constituída por 153 professores de vários agrupamentos do norte de Portugal. Para coleta de dados pessoais e profissionais utilizou-se um questionário sociodemográfico; foi utilizado também escala de autoeficácia na Implementação de Práticas Inclusivas (SHARMA; LOREMAN; FORLIN, 2012). Percebeu-se diferenças devido a variáveis pessoais dos docentes como gênero, idade, habilitação, tempo de serviço, situação contratual, bem como a formação e a experiência com crianças especiais; percebeu-se ainda, que professores autoeficazes, estão mais aptos a práticas inclusivas. Por isso, sugere uma relação de proximidade entre as universidades e as escolas para aprimoramento dos docentes nas práticas inclusivas e avaliações contínuas sobre o trabalho desenvolvido.

Nos estudos apresentados evidenciou-se a referência dos docentes em relação a formação adequada para se desenvolver uma educação inclusiva de qualidade. Ainda, que a crenças de autoeficácia docente podem ser um contributo na formação desses profissionais para saber lidar com situações adversas no cotidiano.

\subsection{Artigos que relacionaram autoeficácia e satisfação no trabalho}

Os estudos encontrados nas bases de dados que apresentam as categorias autoeficácia e satisfação no trabalho, simultaneamente, somaram um total de 4 (quatro). Apesar da baixa incidência absoluta o material é significativo por corresponder às categorias embasadas pela Teoria Social Cognitiva.

Nas categorias supracitadas, as variáveis bem-estar docente e burnout apresentaram, maior frequência cada $(\mathrm{f}=2$ ) seguidos de autoestima, trajetória acadêmica, modelo social cognitivo de satisfação, estilo de vida e eficácia coletiva que apresentaram cada ( $f=1)$. Isto pode ser visualidade pela matriz de codificação que resultou na imagem abaixo:

Gráfico 4: Subcategorias identificadas nos artigos que investigaram a autoeficácia e a satisfação no trabalho docente.

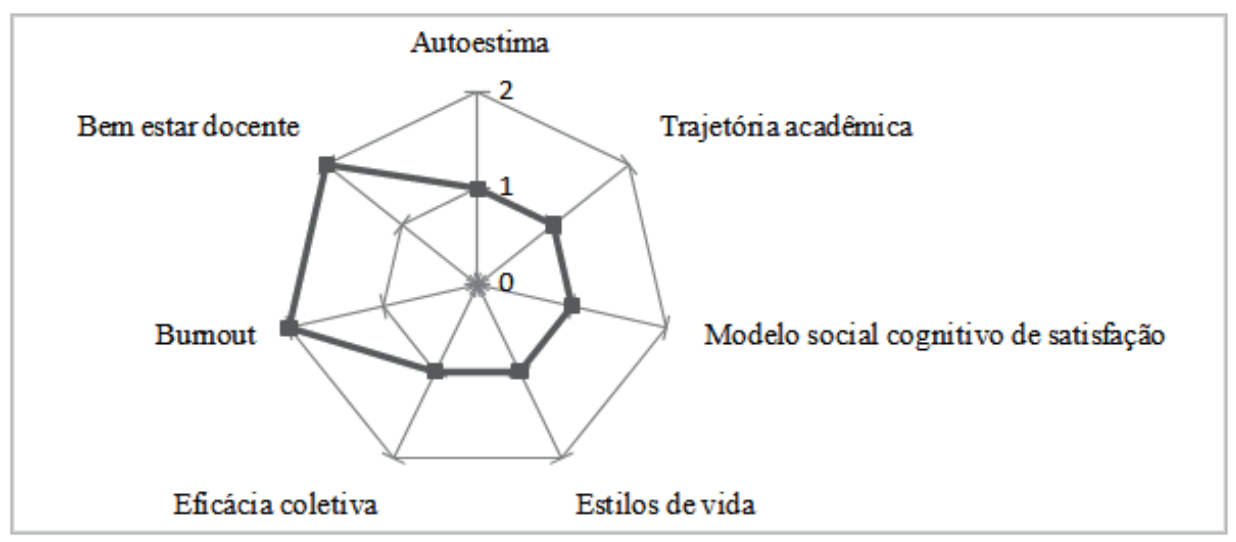

Fonte: Ferreira (2018) 


\subsubsection{Bem-estar docente}

A subcategoria bem-estar docente foi frequente em 2 (dois) estudos que a evidenciam como necessária para o rendimento no trabalho. Assim, Capelo e Pocinho (2014) analisaram a influência da autoeficácia na satisfação profissional ou bem-estar de professores portugueses. Esse estudo tomou como amostra 327 professores do primeiro ciclo básico (trabalham com alunos dos 6 aos 10 anos) que responderam a um questionário de satisfação no trabalho para professores, uma escala de autoeficácia dos professores e, ainda, um questionário de dados sociodemográficos e profissionais. Os resultados evidenciaram que a autoeficácia instrucional aumenta a percepção na relação com a profissão, mas diminui a percepção na relação interpessoal. Percebe-se, dessa forma, que a autoeficácia relacionada à satisfação no trabalho, apesar de melhorar a percepção docente na profissão, ainda precisa ser analisada por outros ângulos e contextos que envolvem o fazer educativo.

laochite et al. (2011) relacionaram a autoeficácia docente com a satisfação pessoal e a disposição em continuar na atividade de ensino. Desse modo, verificaram que a disposição para continuar na docência pode estar relacionada a autoeficácia e a satisfação pessoal ou bem-estar e ser um fator motivador dentro desse processo ensino-aprendizagem. A amostra do tipo não-probabilística foi composta por 220 professores de Educação Física de escolas públicas e privadas, de ambos os sexos e a faixa etária média foi de 25,4 anos. Foi utilizado um questionário de caracterização do participante e de sua atividade docente, composto por questões fechadas e relativas a idade, sexo, tempo de docência, tipo de escola. O resultado mostrou que professores com alta satisfação pessoal com a docência mostraram-se mais autoeficazes para lidar com situações do cotidiano escolar, o que o estimula a continuar na docência. Desse modo, a satisfação pessoal ou bem-estar docente pode contribuir com a autoeficácia, que por sua vez contribui com a qualidade no trabalho educativo.

\subsubsection{Burnout}

O Burnout é uma síndrome desenvolvida a partir de situações estressantes no local de trabalho (CARLOTTO et al., 2015). É um assunto bastante discutido e, um problema, que tem se ampliado no contexto educacional. Por isso, a necessidade de aprofundamento e reflexão sobre o assunto é essencial para a melhoria da qualidade de vida dos professores (SILVA et al., 2008). Apesar da evidência deste assunto em vários estudos (CARLOTTO, 2002; SOUSA et al., 2009; DÍAZ BAMBULA et al., 2012) poucos apareceram relacionados a professores da Educação Básica e a Teoria Social Cognitiva. Assim, nesta busca, a frequência desta subcategoria esteve presente em 2 (dois) estudos.

Carlotto (2012) em seu estudo, objetivam avaliar se a autoeficácia funciona como variável mediadora entre a sobrecarga de trabalho e as dimensões do burnout. Para isso, utilizaram como instrumento de coleta de dados, o questionário para avaliação da síndro- 
me de burnout, versão para professores, a escala geral de autoeficácia e a subescala de sobrecarga laboral da organização Stress Questionnaire. Participaram da pesquisa 982 professores de escolas públicas e privadas. O resultado deste estudo sugere a necessidade de intervenções para o desenvolvimento da autoeficácia em professores como meio de prevenir ou reabilitar da síndrome do Burnout.

Gismero-González et al. (2012) mostram em seus estudos as situações de estresse às quais são expostos os docentes, que podem pôr em jogo seu bem-estar psicológico. Por isso, são utilizadas estratégias de enfrentamento cognitivo que possam neutralizar essas situações de estresse. Desse modo, este estudo analisa essas estratégias com a autoeficácia e as variáveis de trabalho. Utilizou-se como instrumento para coleta um questionário para avaliar três diferentes tipos de estressores em uma amostra de 413 professores de escolas públicas e privadas. Os resultados sugerem intervenções para prevenir o estresse a nível educativo, bem como melhorar o local de trabalho, desenvolver formações que auxiliem a prática cotidiana e auxiliem os docentes a perceberem-se mais eficazes.

A codificação dos objetivos dos estudos relacionados à categoria "satisfação no trabaIho e autoeficácia" resultaram em variáveis que podem sofrer influência desses construtos. Em se tratando dos estudos aqui apresentados, bem-estar docente e burnout apresentaram cada $(f=2)$ de incidência, seguidos de autoestima, trajetória acadêmica, estilo de vida e eficácia coletiva que apresentaram $(\mathrm{f}=1)$ cada. É importante salientar que o percentual aqui apresentado quanto aos resultados seja referente aos objetivos dos estudos sobre autoeficácia ou sobre autoeficácia e satisfação simultaneamente refere-se a incidências de variáveis nos artigos e não referente a quantidade dos artigos encontrados para esta análise.

\subsubsection{Estudos que investigaram exclusivamente a satisfação no trabalho docente}

Os estudos com base na Teoria Social Cognitiva cujo foco é a satisfação no trabaIho ainda são escassos na literatura da área, porém, os trabalhos desenvolvidos sobre o assunto avaliam essa categoria a partir de aspectos cognitivos e afetivos, considerando tratar-se de uma categoria que pode estar diretamente relacionada às percepções sobre a profissão, as crenças e a atuação em sala de aula dos docentes.

Nas buscas apareceram apenas 2 (dois) estudos. Anaya Nieto e Lópes-Martín (2015) estudaram a satisfação no trabalho de professores da educação secundária. A pesquisa contou com uma amostra de 2943 professores de escolas públicas distribuídas por todo país e os dados foram coletados pela pesquisa Procedimento (uma versão online da escala de satisfação no trabalho) - versão professores (ESL-VP). Os resultados indicaram que os professores, de modo geral, apresentam satisfação média, no entanto com grande discrepância em relação às dimensões que as proporcionam. Isto significa que a satisfação não provém de um único fator motivador.

O estudo desenvolvido por Ramos et al. (2016), busca identificar fatores relacionados à satisfação no trabalho e à eficácia coletiva docente. Nesta pesquisa utilizou-se o Mo- 
delo Social Cognitivo de Satisfação no Trabalho (MSCST) de Duffy e Lent (2009) que utiliza um grupo de variáveis para explicar a satisfação do professor. Nesta pesquisa foi usada uma amostra de 495 professores de uma rede privada de ensino. Os resultados indicaram que as crenças de eficácia (autoeficácia e eficácia coletiva) não têm efeito direto, senão que indiretos, sobre a satisfação no trabalho docente; outros fatores, como os econômicos, podem estar mais relacionados. O resultado deste estudo discordou da literatura que trata do assunto, isso pode, no entanto, alertar pesquisadores em educação que não se pode dar como definitivo um único resultado. Em se tratando de seres humanos, como lembra Bandura (2008), vários são os fatores que contribuem para sua percepção sobre os acontecimentos. O sujeito não está isolado e vive numa relação de reciprocidade triádica entre fatores pessoais, ambientais e comportamentais em rápidas e constantes mutações.

\section{CONSIDERAÇÕES FINAIS}

A revisão sistemática mostrou o panorama de estudos em língua portuguesa e espanhola dos últimos dez anos relacionados à autoeficácia e satisfação no trabalho de professores da educação básica subsidiados pela Teoria Social Cognitiva. Os resultados revelaram várias subcategorias associadas aos constructos supracitados, por isso, a importância de se avaliar o contexto educativo no qual os docentes estão inseridos.

A literatura apresentou como importante subcategoria relacionada a autoeficácia o desempenho docente; esta subcategoria revela que o docente precisa acreditar em suas capacidades para desempenhar suas funções com mais qualidade; em relação às subcategorias relacionadas tanto à autoeficácia quanto à satisfação no trabalho foram reveladas: bem-estar docente e burnout. Este resultado mostra que a associação entre essas categorias pode contribuir com a qualidade de vida dos docentes visto que conduz ao bem-estar e este, por sua vez, evita problemas que possam levar ao burnout. Estudos relacionados exclusivamente à satisfação no trabalho docente ainda são bastante escassos, por isso, foram encontrados apenas dois, mas significativos quanto ao resultado que apresentaram, pois, revelam um construto importante para a motivação, resiliência, bem-estar entre outros fatores que contribuem com a vida pessoal e profissional dos docentes.

Pode-se tomar como limitações os critérios estabelecidos para inserção dos estudos a serem analisados. Por isso, sugere-se que outros critérios possam ser utilizados incluindo outras línguas estrangeiras, de modo a ampliar as amostras. Além disso, sugere-se o uso de outros instrumentos de análise para que os dados sejam explorados ao máximo. Apesar das limitações é perceptível o grau de importância dos construtos autoeficácia e satisfação no trabalho na vida laboral dos docentes, portanto, são resultados que precisam ser considerados e analisados para melhoria do trabalho educativo e bem-estar docente. 


\section{REFERÊNCIAS}

ALMEIDA, Alana Peixoto de; LIMA, Flávia Maria Vasconcelos; LISBOA, Sheila Marques; LOPES, Andressa Pereira; JÙNIOR, Alberto José de Amorim Franco. Comparação entre as teorias de aprendizagem de Skinner e Bandura. Caderno de Graduação - Ciências Biológicas e da Saúde. v.1, n.3, Maceió, nov. 2013. pp. 81-90.

ALVES, Giovanni. Trabalho e Subjetividade: o espírito do toyotismo na era do capitalismo manipulatório. São Paulo: Boitempo, 2011.

APABLAZA, Carmem G. Covarrubias; LIRA, Michelle Mendonza. La Teoria de autoeficacia y el desempeño docente: el caso de Chile. Estudios hemisféricos y polares. Volumen 4, $n^{\circ} 2$ (AbrilJunio, 2013), pp. 107-123.

ANAYA-NIETO, Daniel; LÓPES-MARTIN, Estér. Satisfacción laboral del profesorado de educación secundaria. Revista de Investigación Educativa, vol. 33, núm. 2, 2015, pp. 435-452. Murcia, España.

ANDRADE, Thiago Francisco de; BARBOSA, Silvânia da Cruz; SOUZA, Sandra; MOREIRA, Jansen Souza. Valores humanos e satisfação no trabalho de professores e servidores técnicoadministrativos de uma universidade pública. Revista Psicologia: Organizações e Trabalho, 15(4), outdez 2015, pp. 397406.

ANTUNES, Ricardo. Adeus ao Trabalho? Ensaio sobre as metamorfoses e a centralidade do mundo do trabalho. 15. ed. Campinas, SP: Editora a UNICAMP, 2015.

AZZI, Roberta Gurgel; VIEIRA, Diana A (Org.). Crenças de Eficácia em contexto educativo. São Paulo: Casa do Psicólogo, 2014.

AZZI, Roberta Gurgel. Introdução à teoria social cognitiva. Série Teoria Social Cognitiva em contexto educativo. São Paulo: Casa do Psicólogo, 2014.

BANDURA, Albert. Self-efficacy. In V. S. Ramachaudran (Ed.), Encyclopedia of human behaviour. v. 4,. New York: Academic Press, 1994, pp. 71-81.

BANDURA, Albert. Social Cognitive Theory: an agentic perspective. Asian Journal of Social Psychology. v.2, 1999, pp. 21-41.

BANDURA, A. Social cognitive theory of personality. In: PERVIN, L; JOHN, O. (ed.). Handbook of personality. 2. ed. New York: Guilford Publications, 1999, pp. 154-196.

BANDURA, Albert. Exercise of Human Agency Through Collective Efficacy. American Psychological Society. V. 9, n. 3. June, Stanford, California, 2000, pp. 75-78.

BANDURA, Albert. A evolução da teoria social cognitiva. In BANDURA, Albert; AZZI, Roberta Gurgel; POLYDORO, Soely (Org.). Teoria Social Cognitiva: conceitos básicos. Porto Alegre: Artmed, 2008, pp. 14-39.

BARDIN, Laurence. Análise de Conteúdo. Lisboa - Portugal: Edições 70, 1977. 
BUSTOS-NAVARRETE, Cláudio Henrique. Creencias docente e uso de Nuevas tecnologias de la información y comunicación em professores de cinco establecimientos chilenos de educación básica y média. Universitas Psychologica, n.11, v., n. 2, Bogotá, Colombia, 2012, pp. 511-521.

CAPELO, Regina; POCINHO, Margarida. Autoeficácia docente: predição e satisfação dos professores. Educar em Revista, n.54, octubre-diciembre, 2014, pp. 175-184.

CARLOTTO, Mary Sandra. A Síndrome de Burnout e o trabalho docente. Psicologia em Estudo, v. 7, n. 1, jan./jun. Maringá, 2002, p. 2129.

CARLOTTO, Mary Sandra. A síndrome de Burnout e o trabalho docente. Psicologia em Estudo, v. 7 n.1, jan./jun. Mringá, 2012, pp.21-29.

CARLOTTO, Mary Sandra; DA SILVA DIAS, Sofia Raquel; BRITO VIDAL BATISTA, Jaqueline; DIEHL, Liciane. O papel mediador da autoeficácia na relação entre a sobrecarga de trabalho e as dimensões de Burnout em professores. Psico-USF, v. 20, n.1, enero-abril, São Paulo, 2015, pp.13-23.

CASANOVA, Daniela Couto Guerreiro; AZZI, Roberta Gurgel. Análise sobre variáveis explicativas da autoeficácia docente. Educar em Revista, núm. 58, octubre-diciembre, Paraná, 2015, pp. 237-252.

CASTRO-CARRASCO et al. La auto-eficacia docente para la resolución de conflictos entre profesores. Educ. Educ. vol. 15, n. 2, , 2012. pp. 265-288.

COVARRUBIAS, Carmen Gloria; LIRA, Michelle Mendoza. Sentimiento de autoeficacia en una muestra de profesores chilenos desde las perspectivas de género y experiência. Estudios Pedagógicos, $\mathrm{XLI}, \mathrm{n}^{\circ} 1,2015$, pp. 63-78.

COVARRUBIAS-APABLAZA, C. G. y MENDOZA-LIRA, M. C. Determinantes e impacto de los sentimientos de autoefi cacia en los profesores. Educ. Educ., 19 (3), Septiembre-Diciembre de 2016, pp. 339-354.

COUTO, Maria João Baptista Lynch Ferreira. Autoeficácia e satisfação no trabalho em Técnicos de Diagnóstico e Terapêutica. Dissertação (mestrado). Instituto Superior de Contabilidade e Administração do Porto. Porto, 2012.

DALL ROSSO, Sadi. Mais Trabalho!: A intensificação do labor na sociedade contemporânea. São Paulo: Boitempo, 2008.

DIAS, Paulo C. A auteficácia dos professores para a implementação de práticas inclusivas: contributos para uma reflexão sobre a inclusão educativa. Ensaio: aval.pol.públ. Educ., v. 25, n. 94, jan./ mar, Rio de Janeiro, 2017.

DÍAZ BAMBULA, Fátima; LÓPEZ SÁNCHEZ, Ana María; VARELA ARÉVALO, María Teresa Factores asociados al síndrome de burnout en docentes de colegios de la ciudad de Cali, Colombia. Universitas Psychologica, vol. 11, núm. 1, enero-marzo, Bogotá, 2012. pp. 217-227.

DUFFY, R. D.; LENT, R.W. Test of a social cognitive model of work satisfaction in teachers. Journal of vocational Behavior, v. 75, n. 2, 2009, pp. 212-223. 
FARIAS, Gelcemar Oliveira et. Al. Satisfação com o trabalho docente: uma abordagem com professores de educação física. Anais do XVIII Congresso Brasileiro de Ciências do Esporte (CONBRA$\mathrm{CE}$ ), $\vee$ Congresso Internacional de Ciências do Esporte (CONICE), BrasíliaDF, de 02 a 07 de agosto de 2013.

FERNANDEZ, Ana Patrícia de Oliveira. Crenças de Eficácia de Professores no Contexto de Ensino. Tese (Doutorado). Programa de PósGraduação em Teoria e Pesquisa do Comportamental. UFPA, 2015.

FERNÁNDEZ-ARATA, José Manuel. Desempeño docente y su relación con orientación a la meta, estrategias de aprendizaje y autoeficacia: un estudio con maestros de primaria de Lima, Peru. Universitas Psychologica, vol. 7, n. 2, mayo-agosto, Bogotá-Colômbia, 2008, pp. 385-401.

FERREIRA, Enizete A. Autoeficácia e satisfação no trabalho de docentes-alunos do Parfor. Dissertação (Mestrado). Programa de Pós-Graduação em Educação da Universidade Federal do Pará. Belém, 2018.

FIGUEIREDO, Jussara Moore de. Estudo sobre a satisfação no trabalho dos profissionais de informação de uma IFES. Dissertação (Mestrado) Universidade Federal Fluminense, Niterói, 2012.

GATTI, Bernadete A. Estudos quantitativos em educação. Educação e Pesquisa, São Paulo, v.30, n.1, p. 11-30, jan./abr. 2004.

GISMERO-GONZÁLEZ, M. Elena; BERMEJO, Laura; PRIETO, María; CAGIGAL, Virginia; GARCÍA MINA, Ana; HERNÁNDEZ, Vicente. Estrategias de afrontamiento cognitivo, auto-eficacia y variables laborales. Orientaciones para prevenir el estrés docente. Acción Psicológica, v. 9, n. 2, diciembre, Madri, 2012. pp. 87-96.

GLAT, Rosana; PLETSCH, Márcia Denise; FONTES, Rejane de Souza. Educação Inclusiva \& Educação Especial: propostas que se complementam no contexto da escola aberta à diversidade. Revista Centro de Educação. vol.32, n. 02, 2007, pp. 343-355.

GONZÁLES, Teresa Maria Perandones; TORRES, Lucia Herrera; CARRERES, Asunción Lledó. Felicidad subjetiva y autoeficacia docente en profesorado de República Dominicana y España. Psychology and Education. vol. 3, n. 3, dez/2013, pp. 277-288.

GOYA, Alcides; BZUNECK, José Aloyseo,; GUIMARÃES, Sueli Édi Rufini,. Crenças de eficácia de professores e motivação de adolescentes para aprender física. Psicologia Escolar e Educacional, vol. 12, núm. 1, enero-junio, 2008, pp. 51-67.

GUERREIRO CASANOVA, Daniela Couto; POLYDORO, Soely Aparecida Jorge. Autoeficácia na Formação Superior: percepções durante o primeiro ano de graduação. Psicologia: Ciência e Profissão, 31 (1), Campinas, 2011, pp. 50-65.

IAOCHITE, Roberto Tadeu; AZZI, Roberta Gurgel; POLYDORO, Soely Aparecida Jorge; WINTERSTEIN, Pedro José. Autoeficácia docente, satisfação e disposição para continuar na docência por professores de educação física. Rev. Bras. Ciênc. Esporte, Florianópolis, v. 33, n. 4, out./dez. 2011, pp. 825-839.

JUNIOR, Rubens Venditti; WINTERSTEIN, Pedro José. Ensaios sobre a Teoria Social Cognitiva de Albert Bandura. Parte I: conceito de auto-eficácia e agência humana, como referenciais para a área 
da Educação Física e Esportes. Revista Digital. Buenos Aires, Año 15, n 144, Mayo de 2010. pp. 1-1, http://www.efdeportes.com, acesso em: 10.06.2016.

LEMOS, Maithe de Carvalho e; PASSOS, Joanir Pereira. Satisfação e frustração no desempenho do trabalho docente em enfermagem. REME - Rev. Min. Enfermagem; 16 (1), jan./mar., 2012, pp. 4855.

MACHADO, Maria de Lourdes et al. Uma Análise da Satisfação e da Motivação dos Docentes no Ensino Superior Português. Revista Lusófona de Educação, 17, Lisboa, 2011, 167181.

MARQUEZE, Elaine Cristina; MORENO, Claudia Roberta de Castro. Satisfação no trabalho e capacidade para o trabalho entre docentes universitários. Psicologia em Estudo, v. 14, n. 1, jan. /mar, Maringá, 2009, pp. 7582.

PAIVA, Mirella Lopez Martini Fernandes; PEREIRA DEL PRETTE, Zilda Aparecida. Crenças docentes e implicações para o processo de ensino-aprendizagem. Psicologia Escolar e Educacional, vol. 13, n. 1, jan-jun, Paraná, Brasil, 2009, pp. 75-85.

PAJARES, Frank. SelfEfficacy Beliefs in Academic Settings. Review of Educational Research. Winter, vol. 66, n 4, 1996, pp.543-578.

PAJARES, Frank; OLAZ. Teoria social cognitiva e autoeficácia: Uma visão geral. In BANDURA, Albert; AZZI, Roberta Gurgel; POLYDORO, Soely (Org.). Teoria Social Cognitiva: Conceitos básicos. Porto Alegre: Artmed, 2008, pp. 97-114.

PAULA, Alexandre Pinto Vieira de; QUEIROGA, Fabiana. Satisfação no trabalho e clima organizacional: A relação com autoavaliações de desempenho. Revista Psicologia: Organizações e Trabalho, 15 (4), out-dez, Brasília, 2015, pp. 362-373.

PEDRO, Neuza Sofia Guerreiro. Autoeficácia e satisfação profissional dos professores. Dissertação (mestrado). Instituto superior de psicologia aplicada. Lisboa, 2007.

PEDRO, Neusa Sofia Guerreiro; PIEDADE, João. Efeitos da formação na autoeficácia e na utilização educativa das tic pelos professores: estudo das diferenças entre regimes formais e informais de formação. Revista e Curriculum, n.11 v. 3 set./dez. São Paulo, 2013. pp. 766-793.

RAMOS, Maély Ferreira Holanda. Modelo Social Cognitivo de Satisfação no trabalho: percepções sobre a docência. Tese (Doutorado). Programa de pós-graduação em teoria e pesquisa do comportamento. Universidade Federal do Pará. Belém, 2015.

RAMOS, Maély Ferreira Holanda et al. Satisfação no trabalho docente: uma análise a partir do modelo social cognitivo de satisfação no trabalho e da eficácia coletiva docente. Estudos de Psicologia, 21(2), abr-jun. de 2016, pp. 179-191.

ROCHA, Diego Marceli. Crencas de autoeficácia e práticas docentes: uma análise de professores de física em um contexto de inovação. Dissertação de Mestrado. Instituto de Educação, Instituto de Física, Instituto de Química, Instituto de Biociências. Faculdade de Educação da Universidade de São Paulo, 2011. 
RODRÍGUEZ, Susana; NÚÑEZ, José C.; VALLE, Antonio; BLAS, Rebeca; ROSARIO, Pedro. Autoeficacia docente, motivación del profesor y estrategias de enseñanza. Escritos de Psicología. vol. 3, n. 1, diciembre, Málaga, Espanha, 2009, pp. 17.

SANTOS, Fernanda Marsaro dos. Análise de conteúdo: a visão de Laurence Bardin. Resenha de: [BARDIN, L. Análise de conteúdo. São Paulo: Edições 70, 2011, 229p.] Revista Eletrônica de Educação. São Carlos, SP: UFSCar, v.6, no. 1, pp. 383387, mai. 2012. Disponível em http://www. reveduc.ufscar.br.

SANINI, Cláudia; BOSA, Cleonice Alves. Autismo e inclusão na educação infantil: Crenças e autoeficácia da educadora. Estud. Psicol. (Natal), v. 20, n. 3, Natal, set. 2015, p.173-183.

SILVA, Maria Cristina Sant'Anna da; LAURET, Liana. O senso de auto-eficácia na manutenção de comportamento promotores de saúde de idosos. Revista Esc. Enferm. Usp. 2010, pp. 61-67.

SILVA, J. P.; DAMÁSIO, B. F.; MELO, S. A., \& AQUINO, T. A. A. Estresse e Burnout em Professores. Revista Fórum Indentidades, 3(2), 2008, pp. 75-83.

SILVA, Rudiany Reis da. Consciência de autoeficácia: uma perspectiva sociocognitiva para o estudo da motivação de professores de piano. Dissertação (Mestrado em Música). Departamento de Artes, Setor de Ciências Humanas, Letras e Artes, Universidade Federal do Paraná. Curitiba, 2012.

SILVA, José Castro; SILVA, Manuela Marques. Colaboração entre professores e autoeficácia docente: que relações? Revista Portuguesa de Educação, vol. 28, n. 2, Braga, Portugal, 2015, pp. 87-109.

SOUSA, Ivone Félix de; MENDONÇA, Helenides; ZANINI, Daniela Sacramento. Burnout em docentes universitários. Revista Psicologia e Saúde, n.1, v.1, 2009, pp. 1-8.

TORISU, Edmilson Minoru; FERREIRA, Ana Cristina. A teoria social cognitiva e o ensino-aprendizagem da matemática: considerações sobre as crenças de autoeficácia matemática. Ciências \& Cognição. Vol. 14 (3), 2009, , pp.168-177. 